\title{
Pensar la biografía
}

\author{
MARY KAY VAUGHAN
}

omo escribe David Nasaw en su introducción a la "Mesa redonda sobre historiadores y biografía”, publicado en 2009 en American Historical Review, los historiadores han considerado la biografía como una forma menor de disciplina: un supuesto cuento "de la cuna hasta la tumba", en el cual el contexto histórico no es más que un telón de fondo (Nasaw, 2009: 573). En 1979, observa Nasaw, Oscar Handlin vio a la biografía como "un género aparte de la historia", por su enfoque en la personalidad y el carácter del individuo, temas que el historiador no tomaba en cuenta (Handlin, citado en Nasaw, 2009: 374). Otros piensan que el historiador es incapaz de escribir una biografía porque siempre privilegiará el evento sobre el individuo. Por el contrario, Nasaw argumenta que la mayoría de las biografías hechas por los historiadores exploran el vínculo entre el contexto y el individuo. Esas biografías "se refieren al individuo en el estudio del mundo fuera de ese individuo con el interés en cómo lo privado informa lo público y viceversa" (Nasaw, 2009: 574).

En la misma mesa redonda, Alice Kessler-Harris sugirió que la biografía permite echar un vistazo a un conjunto más amplio: "un camino distinto hacia el pasado" (Kessler-Harris, 2009: 626). Por otra parte, explicó que en su biografía de William Blake, E. P. Thompson intentó explorar cómo la mente del poeta "encontró al mundo"

Thinking Biography

MARY KaY VAUGHAN

Universidad de Maryland, Maryland, Estados Unidos mkv@umd.edu

Desacatos 50, enero-abril 2016, pp. 88-99 (Thompson, citado en Kessler-Harris, 2009: 626). De manera que en la biografía, argumenta Harris, el individuo se transforma en un "hecho - más complicado que la mayoría de los hechos, pero capaz de iluminar el pasado en formas nuevas y provocadoras-" (KesslerHarris, 2009: 626). Un acercamiento semejante puede descubrir el cruce de aquellos procesos históricos complicados que la historia macro muchas veces no puede ver, como lo muestra Mílada Bazant en su ensayo publicado en este número de Desacatos. O bien, la biografía puede atrapar aspectos de la vida privada que resultan clave para entender la vida pública de un individuo, como lo hace notar Eric Van Young en su trabajo. La biografía puede explorar las contradicciones de 
la autoconstrucción pública de una persona en relación con los contextos históricos, como apunta Daniela Spenser. Asimismo, en la propuesta de Aurelia Valero Pie, la biografía puede analizar las nociones autoconstruidas de un individuo: cómo éstas se modifican al tiempo que cambian los paradigmas de lo que es y debe ser un individuo.

El nuevo aprecio por la biografía refleja una acumulación del conocimiento histórico, de sus métodos y de la teoría. La historia social y la historia cultural nos han alejado de la historia de los grandes hombres. Han aportado un conocimiento de las vidas de la gente común y de las estructuras socioeconómicas, políticas y lingüístico-discursivas que las moldean. La nueva biografía responde a los desafíos de la historia social y la historia cultural: no se trata sólo de las estructuras que forman al individuo, sino de cómo el individuo las negocia. Tomando en cuenta las ideas de Merleau Ponty, Michel de Certeau, Anthony Giddens y Andreas Reckwitz, Gabrielle Spiegel sugiere una fenomenología social...

basada en la reevaluación del actor individual como sujeto histórico [...] una creencia en la percepción individual como la propia estructura del conocimiento y acción del agente en el mundo - una percepción mediada y tal vez encerrada, pero no controlada completamente por el andamiaje cultural o los esquemas conceptuales, dentro de los cuales tiene lugar- (Spiegel, 2008: 402).

El individuo puede navegar en las estructuras cambiantes no sólo al responder a ellas, sino al participar en su creación y su destrucción, como hacen todos los individuos analizados en estos ensayos. Al mismo tiempo, la biografía puede explorar las tensiones entre una parte y su conjunto cuando las estructuras cambian y los individuos no cambian, como Spenser y Van Young sugieren en sus ensayos sobre Vicente Lombardo Toledano y Lucas Alamán, respectivamente.
El giro hacia la biografía no se explica por completo con el desarrollo de nuestro campo profesional, sino con tendencias históricas más amplias. En la "Mesa redonda", Jochen Hellbeck destaca cómo la biografía, la autobiografía y los diarios disfrutaban de popularidad en la Nueva Inglaterra puritana del siglo XVII como narraciones de las salvaciones del alma (Hellbeck, 2009: 615-616; Gusdorf, 1991: 407). También florecían en la sociedad estadounidense de mediados del siglo XIX, con la creación del modelo de ciudadano ejemplar en un contexto en el cual "la economía del mercado, la religión evangélica y el romanticismo animaban a la gente a pensarse como agentes libres, personas actuando en las mismas plataformas que han creado" (Hellbeck, 2009: 616). En Biography: A Brief History, Nigel Hamilton nota la oleada de este género como una supuesta expresión de la democracia expandida después de la Segunda Guerra Mundial (Hamilton, citado en Hellbeck, 2009: 621). Curiosamente, Hellbeck advierte también el florecimiento de la biografía en la Unión de Repúblicas Socialistas Soviéticas (URSS), donde tomó la forma de un bildungsroman para la transformación de la persona en el ciudadano ideal del colectivo socialista: la biografía hablaba del esfuerzo del individuo para alinearse con las leyes de la historia y del Estado soviético (Hellbeck, 2009: 617-620). Al mismo tiempo, Susan Mann describe la biografía como modelo de conducta y legitimación de las jerarquías de poder que empezó hace siglos en China. Hoy el giro hacia la biografía del historiador profesional no puede disociarse de una plétora de historias de vida y testimonios que salen de las aulas, las cárceles, las clínicas, las organizaciones de mujeres, las asociaciones comunitarias, las notas de campo de los antropólogos y de los sobrevivientes al Holocausto, la guerra, la tortura política, los desastres naturales y los movimientos revolucionarios, por no mencionar las confesiones de la vida privada y la búsqueda de los consejos que inundan la televisión. Para muchos autores, la autobiografía es 
una forma vernácula de psicoterapia, y hasta un psicoanálisis, no muy diferente de lo que era para José Gaos, examinado aquí por Aurelia Valero Pie. En la actualidad, la evolución de la disciplina permite la aceptación de la biografía como algo históricamente significativo, que forma parte de un contexto social marcado por 1) el derrumbe de la izquierda y las esperanzas de una colectividad socialista; 2) el énfasis extraordinario en la libertad individual sin apoyos públicos; 3) el declive de la familia tradicional; 4) la pérdida de modelos homogéneos de la identidad y la conducta a favor de los múltiples modelos, siempre en proceso de destrucción/creación. Tal vez, al mismo tiempo, la biografía es el lugar seguro que buscamos en un mundo turbulento que ha superado nuestros paradigmas para interpretarlo. En efecto, tal vez la biografía es ahora existencialmente necesaria.

La Revolución mexicana produjo las memorias y autobiografías de los líderes —e. g. Martín Luis Guzmán, José Vasconcelos, Ramón Beteta, Gonzalo Sánchez, Diego Rivera-, y en seguida las colecciones de las historias orales - e. g. la obra de Eugenia Meyer-. Desde la década de 1960, los géneros del testimonio y la biografía, incluidos lo seminovelesco y lo novelesco, han florecido -Elena Poniatowska, Gustavo Sainz, José Agustín-. En décadas recientes hemos leído las biografías de famosos cantantes y actores del cine, como Pedro Infante, Agustín Lara y Lucha Reyes — escritas por Carlos Monsiváis, Pavel Granados y Guadalupe Loaeza, Alma Velasco-, de mujeres célebres, como Frida Kahlo, Tina Modotti, Leonora Carrington, Antonieta Rivas Mercado y Elena Arizmendi, Laura Méndez de Cuenca — por Elena Poniatowska, Fabienne Bradu, Gabriela Cano, Mílada Bazant- y de las figuras destacadas en la política y la vida intelectual, escritas por Friedrich Katz, Enrique Krauze, Susana Quintanilla, Christopher Domínguez, Carlos Herrejón, Samuel Brunk, Linda Hall, y las obras en proceso de Daniela Spenser, Eric Van Young y Aurelia Valero Pie.
De los cuatro ensayos que integran la sección temática de este número de Desacatos, sólo Múlada Bazant dice por qué ha escogido escribir la biografía de su sujeto. Como historiadora de la educación en el siglo XIX, espera penetrar en la vida cotidiana del maestro Clemente Antonio Neve (1829-1905), como lo hizo en su biografía de Laura Méndez de Cuenca (1853-1928). Tal vez se siente obligada a explicar su propósito porque está escribiendo sobre una personalidad oscura, mientras los otros tres biógrafos exploran las vidas de hombres famosos, con un lugar en la historia que no necesita explicación. Sin embargo, es importante entender la lógica de la selección del sujeto, porque cada biografía es en parte una autobiografía (Brown, 2009: 599). La obra de Eric Van Young cubre la época borbónica y la Independencia. Su exploración de la vida del hombre de Estado conservador Lucas Alamán (1792-1853) es un análisis lúcido de cómo la vida privada informa la vida pública y viceversa. La obra de Daniela Spenser ilumina la historia de la izquierda mexicana, sobre todo en su relación con la Unión Soviética y el movimiento internacional comunista. Su capacidad para leer las fuentes en ruso y otros idiomas le ha dado un lugar privilegiado. Escogió escribir la biografía de Vicente Lombardo Toledano (1894-1968), un actor central en esta relación desde la década de 1920 hasta la de 1960. Entendemos menos la decisión de Aurelia Valero Pie de estudiar la vida de José Gaos (1900-1969), refugiado de la Guerra Civil Española en México y filósofo crítico del desarrollo de los estudios filosóficos en México y Latinoamérica. No nos explica la razón, y como se trata de una académica joven cuya tesis de doctorado fue distinguida con un premio, no hay otras obras suyas que nos den pistas.

Sin embargo, aunque no tengamos una explicación completa acerca de la selección del sujeto, podemos examinar los ensayos en relación con el problema inmediato que cada autor quiere resolver. Eric Van Young examina el "arco de fracaso" 


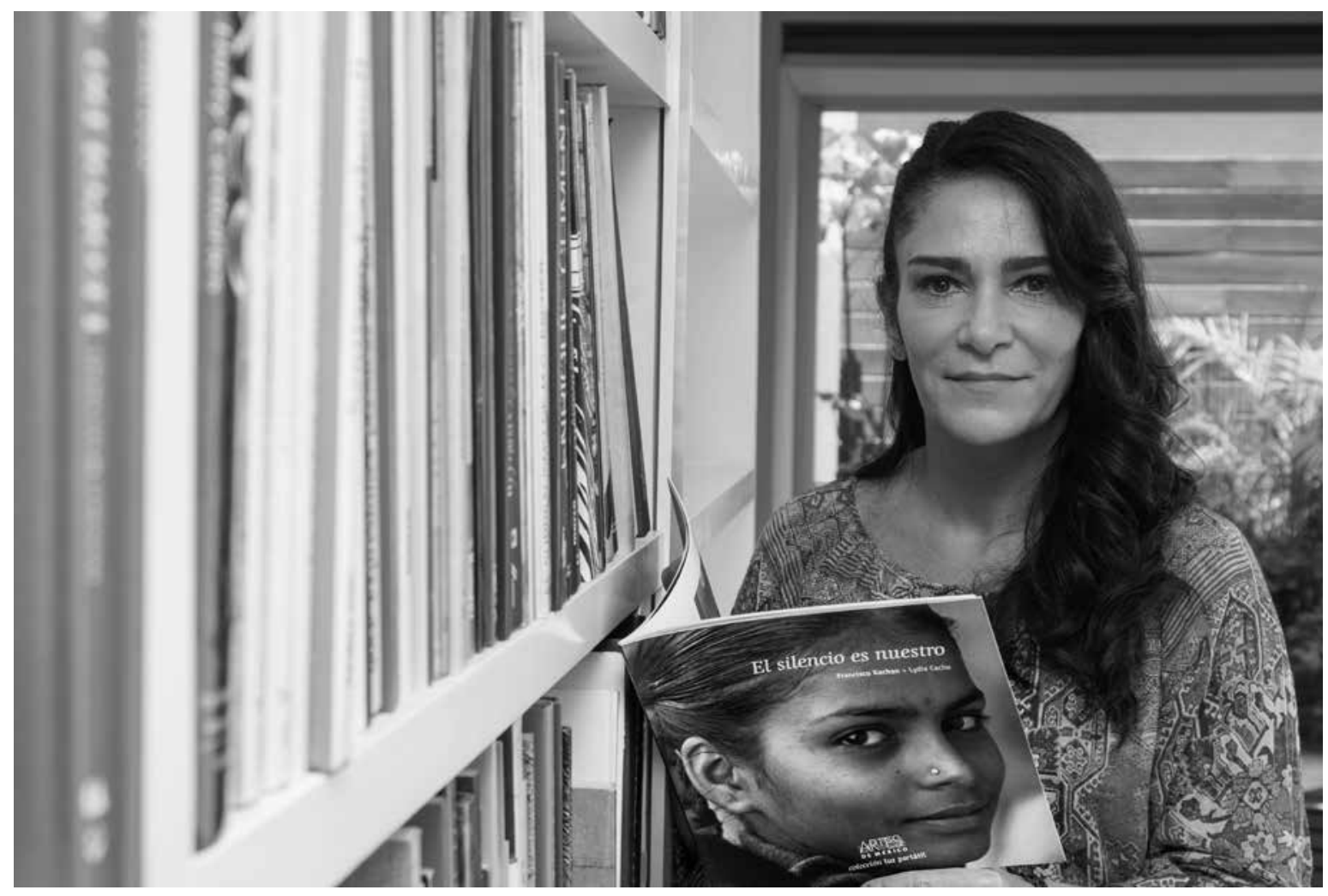

Rodrigo GonZÁLEZ - Lydia Cacho, periodista y defensora de derechos humanos, con el libro que realizó con el fotógrafo Francisco Kochen. Ciudad de México, agosto de 2015 .

en la vida de Lucas Alamán y se mueve entre su vida privada y su vida pública en un análisis basado en su obra escrita. Daniela Spenser utiliza la palabra publicada de Vicente Lombardo Toledano y un abanico de fuentes escritas para reconstruir la historia de la Confederación de Trabajadores de América Latina (CTAL), organización creada por el sujeto en 1938 y disuelta en 1963. Su propósito es mostrar que Vicente Lombardo Toledano es siempre un "yo" público y nunca un "yo" privado, y que su presentación de sí mismo está siempre ajustada a su público y a su noción de las "leyes de la historia". Aurelia Valero Pie se propone examinar el sentido de sí mismo de José Gaos, es decir, su autobiografía según su obra escrita, que revela una tensión entre la filosofía occidental tradicional y su entendimiento del psicoanálisis como un desafío a la pretensión de la filosofía occidental de alcanzar las verdades universales. Vincula el psicoanálisis, el "yo" y la filosofía para salir del paradigma del siglo XIX europeo del individuo - masculino- exclusivamente racional. A diferencia de los otros, Mílada Bazant explora las fuentes visuales como una metodología para penetrar en la experiencia de un maestro de escuela cuya obra escrita se limita a unos libros de texto y una correspondencia dirigida a autoridades e instituciones.

A continuación, quiero examinar dos aspectos: cómo el historiador construye al individuo y cuál es la relación entre el individuo y su contexto. El propósito e interés del historiador siempre influirán en su presentación del individuo. ¿Por qué se escoge a una persona? La noción del sujeto también está 
determinada por las fuentes disponibles y su autoconstrucción. Como Van Young, Spenser y Valero Pie muestran en sus ensayos, la construcción de sí mismo, percibida por la lectura de las escrituras de la persona, es una representación moldeada por la percepción del sujeto de su público. Como Van Young y Spenser notan, esta representación está colmada de inclusiones y exclusiones, y a veces se sale de la pista de la narración intencionada del sujeto, algo que deleita al biógrafo. Como argumenta Jo Burr Margadant, el historiador descubre que su sujeto no es un ser coherente sino una actuación que quiere "crear la impresión de la coherencia, o un individuo con múltiples 'yo' cuyas manifestaciones distintas reflejan los cambios en el tiempo, las exigencias y las opciones de distintos contextos, o la variedad de las maneras en que los otros quieren representar a esta persona" (Margadant, citado en Nasaw, 2009: 576). Los biógrafos, incluyendo a los autores reseñados aquí, intentan entender cómo en un espacio y un momento el individuo está organizado y autopresentado (Nasaw, 2009: 576).

Cada sujeto biografiado en estos ensayos está obligado a negociar los cambios en las estructuras de poder, de la organización sociopolítica y cultural y del discurso. Ninguno de ellos está más problematizado por estos cambios que Lucas Alamán, quien enfrentó la caída del orden Habsburgo-borbónico, las guerras sangrientas y prolongadas de la Independencia, marcadas por un levantamiento popular sin precedentes y una lucha turbulenta, violenta y fracasada para consolidar un nuevo Estado en la primera mitad del siglo XIX. Van Young ilumina la relación entre la vida privada de Alamán y su acción pública en su entendimiento y navegación de estos cambios. Las fuentes principales de Van Young son las memorias de Alamán, su historia de la Nueva España y del México independiente y los archivos de sus negocios. Aquí está una figura brillante de la elite pre y posindependiente que intenta dirigir los acontecimientos y consolidar las instituciones en medio de una tormenta extraordinaria que afecta cada aspecto de la vida, y éstos se suceden en una cascada que no puede controlar. Van Young lo representa como un intelectual y un hombre de Estado de la esfera pública moderna de los primeros años del siglo XIX. En el esquema de Habermas, Alamán es - y se ve a sí mismo- como un actor racional en este espacio de diálogo. Mantiene una separación clara entre la esfera pública de la política y la esfera privada: su hogar es austero, bien ordenado, y las emociones familiares, en apariencia, reprimidas con severidad o al menos escondidas de la vida pública. La familia burguesa nuclear que él dirige como un patriarca parece ser típica. Sin embargo, sus memorias tan críticas en su percepción de sí mismo hablan de una familia precapitalista. Recuerda su linaje largo y aristócrata en Guanajuato y sus negocios. En el lenguaje híbrido de la época borbónica, habla de su herencia de nobleza, su posición de liderazgo y distinción social, pero deplora la pérdida de la fortuna por las herencias desaprovechadas y la gerencia mal implementada. Admira el orden y la jerarquía, pero no el comportamiento precapitalista. En su aprecio, es un hombre que abraza los discursos cambiantes de una época revolucionaria. Es un hombre de la Iluminación y al mismo tiempo un re-actor ante sus revoluciones —admirador del conservador Edmund Burke-, así como un actor innovador y creativo en su respuesta a los desafíos de la construcción del Estado nacional en una nueva época capitalista —admirador de Jeremy Bentham y la industria británica- En sus negocios y políticas, como hombre de Estado, lucha por aplicar los principios de la lógica burguesa. Sin embargo, el retrato se nubla por el contexto inestable. No está en Europa, cuyos criterios ha adoptado, y la esfera pública en la cual opera se encuentra atribulada por las luchas intensas y amargas y la violencia en forma de guerra y asesinatos, en la cual tal vez está involucrado. Se desconcierta por esta esfera pública tensa, por la economía devastada y por la amenaza creciente de 
Estados Unidos. Su desprecio por las masas es a la vez aristocrático y burgués. Cree en un orden jerárquico dirigido por una elite de hombres de carácter y talento superiores. Sin embargo, está abrumado por el contexto y aislado de lo que percibe como vida pública fracasada, reflexiona sobre la historia y sobre sí mismo, entrelaza ambos para producir una historia muy nostálgica y pesimista de su país. Así es el arco que construye Van Young de lo privado y lo público.

De manera distinta, Daniela Spenser representa a Vicente Lombardo Toledano como un individuo totalmente autoconstruido y reconstruido en relación con la vida pública. Casi no tiene vida privada en su autopresentación. En contraste con Alamán, sus raíces no son aristocráticas: viene de una familia inmigrante, de empresarios exitosos de una región remota de México. Ajusta la información que imparte sobre su familia de acuerdo con la percepción de su ser público y su papel histórico imaginado. Su narración excluye más que incluir y así fortifica la noción de un individuo obsesionado por su representación pública. Al contrario que Alamán, cree en "las inexorables leyes históricas", que toma de una ideología del siglo XIX basada en la noción del progreso continuo, la lucha de clases y la victoria segura de la clase obrera y el socialismo. El papel que asume es parecido al de Alamán. En un país atrasado, la historia tiene que estar en manos de una elite iluminada. Pero a diferencia de Alamán, abraza a las masas sólo desde su posición de líder y manipulador. Más importante, se monta sobre la ola de la historia en la primera mitad de su vida pública, lo que le permite desempeñar un papel clave en la formación de la Confederación de Trabajadores de México (СTM), en la ideología posrevolucionaria y en la formación del Estado burgués. Similar a la de Alamán, su trayectoria se convierte en un arco.

Spenser crea el contexto y hace el análisis. Después de la Segunda Guerra Mundial, la configuración de fuerzas que permitió a Vicente Lombardo
Toledano llegar a la cúspide del poder —el populismo de Franklin Roosevelt, presidente de Estados Unidos, y de Lázaro Cárdenas, presidente de México, el auge del sindicalismo extremo en los dos países- cambia drásticamente cuando el país del norte entra en la Guerra Fría y ataca de manera agresiva a los sindicatos y gobiernos radicales de Latinoamérica. Vicente Lombardo Toledano sale de la СTM, que se transforma en una fuerza moderada que coopera con los nuevos gobiernos conservadores de México. Spenser contrasta las "verdades" cambiantes que Lombardo Toledano crea para sus públicos en relación con la CTAL. En su entrevista con Edna y James Wilkie dice que la desintegración de la organización se debe a la Guerra Fría, las intervenciones de Estados Unidos en Latinoamérica y la represión de los movimientos independientes de obreros por los gobiernos conservadores latinoamericanos. Cuando los Wilkie le preguntan si la CTAL ha recibido dinero de la URSS, dice que no, aunque había recibido fondos indirectos de esta fuente, como lo documenta Spenser. Les dice que la CTAL ha cumplido su misión histórica, pero no define qué es eso. Al construir una narración más compleja, Spenser analiza la desintegración de la CTAL con un uso cuidadoso de las fuentes, sobre todo las de la Federación Sindical Mundial (FSM), dirigida por el bloque soviético una vez que los sindicatos "libres" de Europa occidental y Estados Unidos han salido de la organización en 1948. La CTAL desempeñó un papel clave en la FSM. Spenser nota que el imperialismo norteamericano no fue la única fuerza que intervino en el colapso de la CTAL. La autora examina el papel de la URSS, la FSM, los partidos comunistas y sindicatos latinoamericanos afiliados a la CTAL. La URSS y la FSM optaron por una política de colaboración con las confederaciones sindicales moderadas asociadas a Estados Unidos como parte de una nueva estrategia de coexistencia pacífica, pero con las aspiraciones de dinamitarla por dentro. Los partidos comunistas de Latinoamérica aprovecharon esta posición y se unieron a la FSM en 


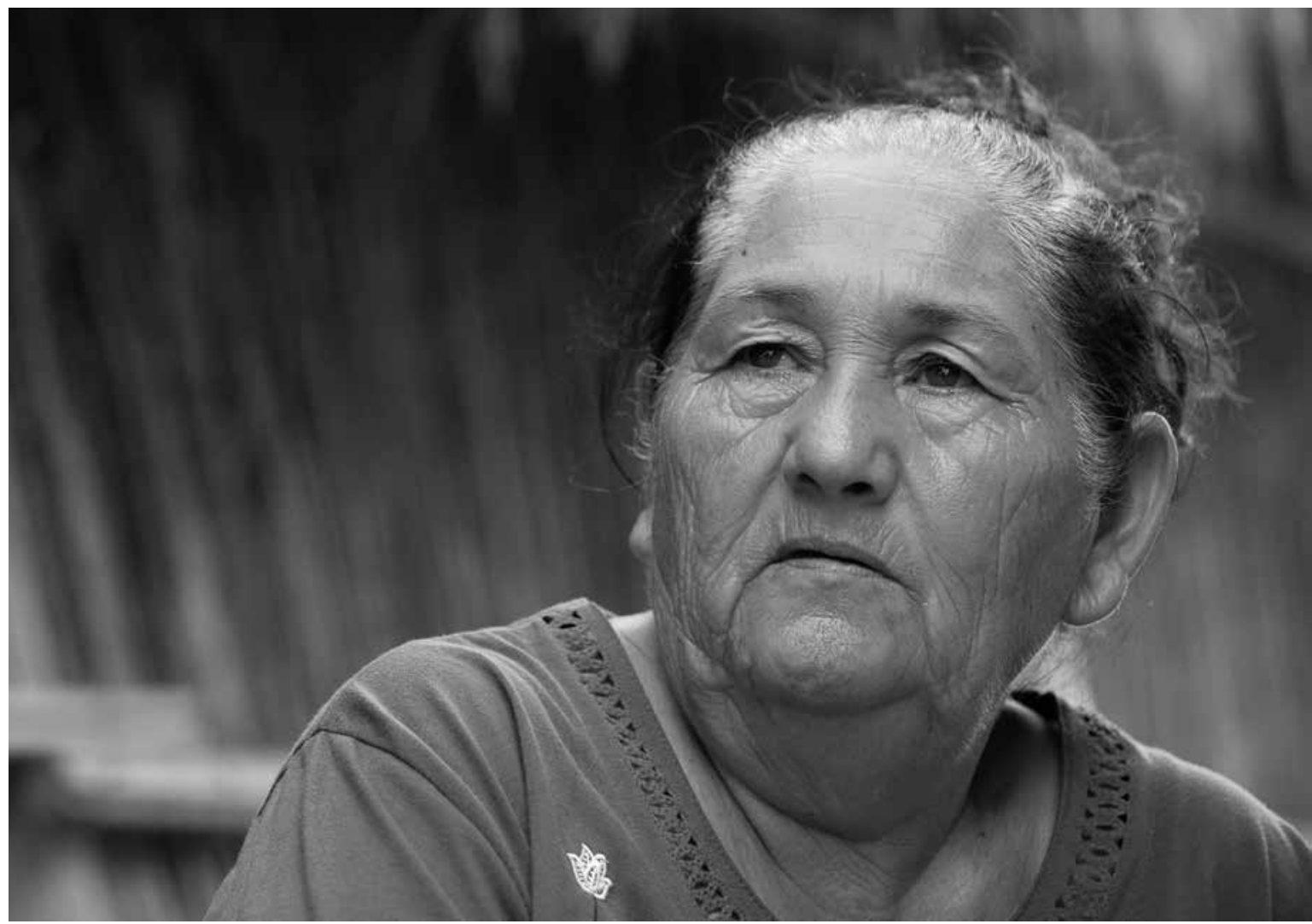

PROMETEO LUCERo • Hilda Hurtado Valenzuela, representante de los pescadores indígenas cucapah. Baja California, México, agosto de 2014.

su crítica a la CTAL como una voz antiimperialista ineficaz y sin una base masiva de obreros. En una conferencia en Río de Janeiro, en 1963, los latinoamericanos aceptaron la disolución de la CTAL y declararon su lealtad, no a la FSM, sino a una nueva etapa de lucha iniciada por la Revolución cubana. Spenser nota que Vicente Lombardo Toledano, en su diálogo con los sindicatos y sus confederaciones, culpó a los partidos comunistas pero exoneró a la URSS. Aunque Lombardo Toledano contaba distintas historias a distintos públicos, no estoy segura de su posición en relación con la desintegración de la CTAL, ya que era inconsistente con su misma trayectoria. Siempre fue leal a la URSS y con frecuencia hostil a los partidos comunistas latinoamericanos, sobre todo al mexicano.
El ensayo de Aurelia Valero Pie sobre José Gaos difiere de los dos análisis de hombres famosos. Habla poco del contexto histórico, fuera de su abstracción como una noción implícita en el pensamiento y la metodología de Gaos. Hubiera sido útil examinar no sólo la influencia de Freud, sino también el impacto de la turbulencia de la guerra y la política europea, y su inmigración a México sobre sí mismo, su trabajo y su vida pública. Por el contrario, el ensayo se enfoca en la construcción de su "yo" en relación con la disciplina de la filosofía. Distinto de Vicente Lombardo Toledano, pero también insertado en los debates del siglo Xx, no cree en las leyes de la historia sino en la historicidad o la idea de que el individuo está moldeado por el tiempo y el espacio. Sus movimientos intelectuales audaces sugieren que 
toda filosofía está anclada en la autobiografía y que el psicoanálisis es herramienta esencial para el autoconocimiento. En contraste con el pensamiento de los filósofos que analiza, Gaos incorpora el subconsciente, lo sexual, lo erótico, lo libidinal. Abandona la noción iluminista del hombre racional, aunque puede argumentarse que su aprecio por lo "irracional" deriva de la tradición iluminista de Rousseau. Está consciente de que los argumentos de Freud han estado incorporados a la vida cotidiana del siglo $\mathrm{XX}$, pese a que tenemos que preguntar si Freud no es más que una expresión de los cambios en marcha y menos el arquitecto de ellos. Al incorporar lo libidinal, Gaos no difiere tanto de Herbert Marcuse, quien en 1955 insistió en que este elemento era central en el ser humano, pero al contrario que Gaos, lo incorporó a la tradición filosófica marxista (Marcuse, 1955).

En un gesto audaz, Gaos argumentó que la voluntad filosófica tenía un origen libidinal: el deseo de poder y dominio. Conceptualizó la trayectoria del filósofo como un arco, similar al que construye Van Young para Lucas Alamán y que Spenser sugiere para Vicente Lombardo Toledano. El arco que crea Gaos empieza con la vocación, basada en el deseo, a la que sigue la decepción y después la obstinación: para él, la continuación de la tarea filosófica después de entender lo insondable del ser del filósofo. Al probar su propia memoria, fracasa en su intento de llegar a recrear la experiencia original porque reconoce que la memoria la cubrió de capas de experiencias y conocimientos subsecuentes y las represiones de las experiencias resistentes a la recuperación. Éstos ya son los principios de la historia oral y de la biografía contemporánea. Lo que no forma parte de la biografía contemporánea es su idea de que al examinarse a sí mismo también está hablando de los otros. No hay nada específico anotado aquí que explique cómo puede hablar de los otros, con excepción de algunas referencias abstractas al tiempo y espacio compartido. En un sentido, está atrapado por la fenomenología tradicional —enfocado en el individuo solitario de la filosofía occidental- y todavía distante de la fenomenología social sugerida por Gabrielle Speigel: una noción de cómo opera el individuo dentro de las estructuras y los discursos que son negociables y aun vulnerables a la destrucción y creación. El intento de Valero Pie es claro y su ensayo está bien argumentado, pero es algo limitado y descontextualizado, de una manera que disminuye la contribución de Gaos a los estudios filosóficos en general y a Latinoamérica y México en lo particular. Su historicismo y relativismo contribuían de manera significativa; primero, en su traducción de las principales obras europeas, sobre todo alemanas, y segundo, en su estímulo muy directo a la investigación filosófica de las realidades sociales y temporales latinoamericanas y a la construcción del individuo adentro de éstas (Magallón, 2009-2010).

Para su biógrafa, Mílada Bazant, Clemente Antonio Neve ofrece un desafío distinto al de los hombres célebres presentados antes. La vida de este maestro indígena que abarca casi todo el siglo XIX representa una ventana hacia la experiencia de los maestros de primaria. La autora ha escrito mucho sobre la educación primaria en esta época y ha publicado una biografía sobresaliente de la maestra y escritora Laura Méndez de Cuenca. Al contrario de los hombres ilustres de la elite y Laura Méndez de Cuenca, Neve escribió poco y nunca estuvo llamado por una corte de justicia a dar testimonio, como Menocchio en El queso y los gusanos, de Carlo Ginzburg, que ha dado a los historiadores un vistazo raro del pensamiento de la gente subalterna en el pasado distante (Ginzburg, 1980). En otro trabajo, Bazant examina los libros de texto y la correspondencia que Neve escribió y que nos dice algo sobre su visión del mundo, y por inferencia, sobre su sentido de sí mismo. Aquí hace algo diferente, explora los espacios por los que caminaba y los lugares en los que habitaba. Bazant arroja luz sobre lo visual: pinturas, litografías, fotografías y mapas. Incorpora la tecnología o bien marca su ausencia: con base en la experiencia 
de caminar muchos kilómetros de la ciudad al pueblo donde trabajaba explica que el maestro no podía comprar o rentar un caballo, mucho menos un carruaje como el que llevó a Maximiliano a su escuela; la ausencia de drenaje moderno en la ciudad, donde la gente orinaba y defecaba en las calles ilustra sus condiciones de vida; la introducción de la fotografía, que cambiaría los sentidos y conceptos de los individuos, le permitió a Neve hacer sus propias tomas.

La autora sostiene correctamente que estos artefactos visuales dan al historiador y al lector una idea descriptiva del mundo y de los espacios del pasado, pero ¿podemos decir que nos dan un sentido de la manera en la cual este mundo era experimentado, percibido y sentido por la gente común y corriente? Bazant está alerta a los peligros de la mirada no mediada por el contexto histórico. Por ejemplo, considera la tesis de Huizinga sobre la Edad Media tardía: la belleza de la obra de arte estaba contrastada con la miseria de la vida cotidiana. Apunta también que las notas y las ilustraciones de los viajeros europeos en México reflejaban una óptica en búsqueda de lo exótico y lo pintoresco. Reconoce que las pinturas telúricas de la ciudad y su paisaje — e. g. la obra de Velasco - captaban una posición estética afinada, relacionada con el estado social, las normas del gremio artístico y la moda europea abrazada con avidez por los mexicanos de cierta clase y formación. ¿Qué belleza de la naturaleza percibía Neve cuando transitaba por un paisaje lleno de peligros y desafíos? Las caminatas nos parecen infinitas y extenuantes, las inundaciones, las lluvias, las epidemias, los animales y los insectos, aun los seres humanos encontrados por el camino son pobladores de una sociedad todavía violenta, jerárquica y racista. Bazant hace referencia a estos desafíos, pero tal vez no los explora suficientemente. Recuerdo que hubo cambios en los libros de texto aprobados por las escuelas primarias en la ciudad de México en la década de 1940. Los textos publicados en el porfiriato y todavía en uso presentaban a la naturaleza como algo peligroso — buques naufragados en el mar oscuro y turbulento, mujeres viejas luchando con la lluvia y la noche- - y merecedora de respeto: el roznido del burro era un mejor pronosticador de la lluvia que el meteorólogo (Camarillo, 1958: 95-101, 155-156, 162-136; Delgadillo, 1942: 97). A finales del porfiriato, todavía no existía una noción clara de la ciencia y la tecnología que sugiriera la manera sustancial en que facilitarían la vida. Los textos escritos en los años treinta y cuarenta ya compartían el culto a la tecnología y actitudes y percepciones alteradas de la naturaleza. Magnificaban su belleza, su bondad ausente de espinas y peligros, y al mismo tiempo, la instrumentalizaban. Con frecuencia, sin mencionar la labor humana y animal requerida, presentaban la naturaleza como proveedora de comida, agua, electricidad y madera para las ciudades en crecimiento (Basurto, 1941: 140, 145, 148-149, 150-161). La percepción de un niño urbano podía diferir mucho de la percepción de uno del campo. Es decir, tenemos que historizar y espacializar la percepción y la experiencia.

Bazant nos presenta una visión fascinante, sensacional, hasta exótica para nuestros sentidos contemporáneos, de las calles fétidas de la ciudad, provocadoras de enfermedades, y vecindades donde las clases baja y media naciente vivían juntas en ausencia casi total de la privacidad burguesa. Compartían los excusados, los fogones, el agua, las camas o los petates y los lavaderos. ¿Qué significaban para Neve esos olores? ¿Se estremecía ante ellos? ¿Juzgaba como impedimentos a la vida familiar y a su tarea de escribir los espacios reducidos y la ausencia de privacidad? Como lo ha explicado Norbert Elias, los sentidos cambian con el tiempo y el espacio. Elias cita un capítulo de Erasmo, escrito en 1530, que instruye a las nuevas asociaciones de seres humanos sobre cómo conducirse en una etapa de transición de la Edad Media a la sociedad europea de la modernidad temprana. Estaba permitido, escribió en Sobre la civilidad y los jóvenes, la ventosidad y el vómito, porque mantener esos malos humores dentro 


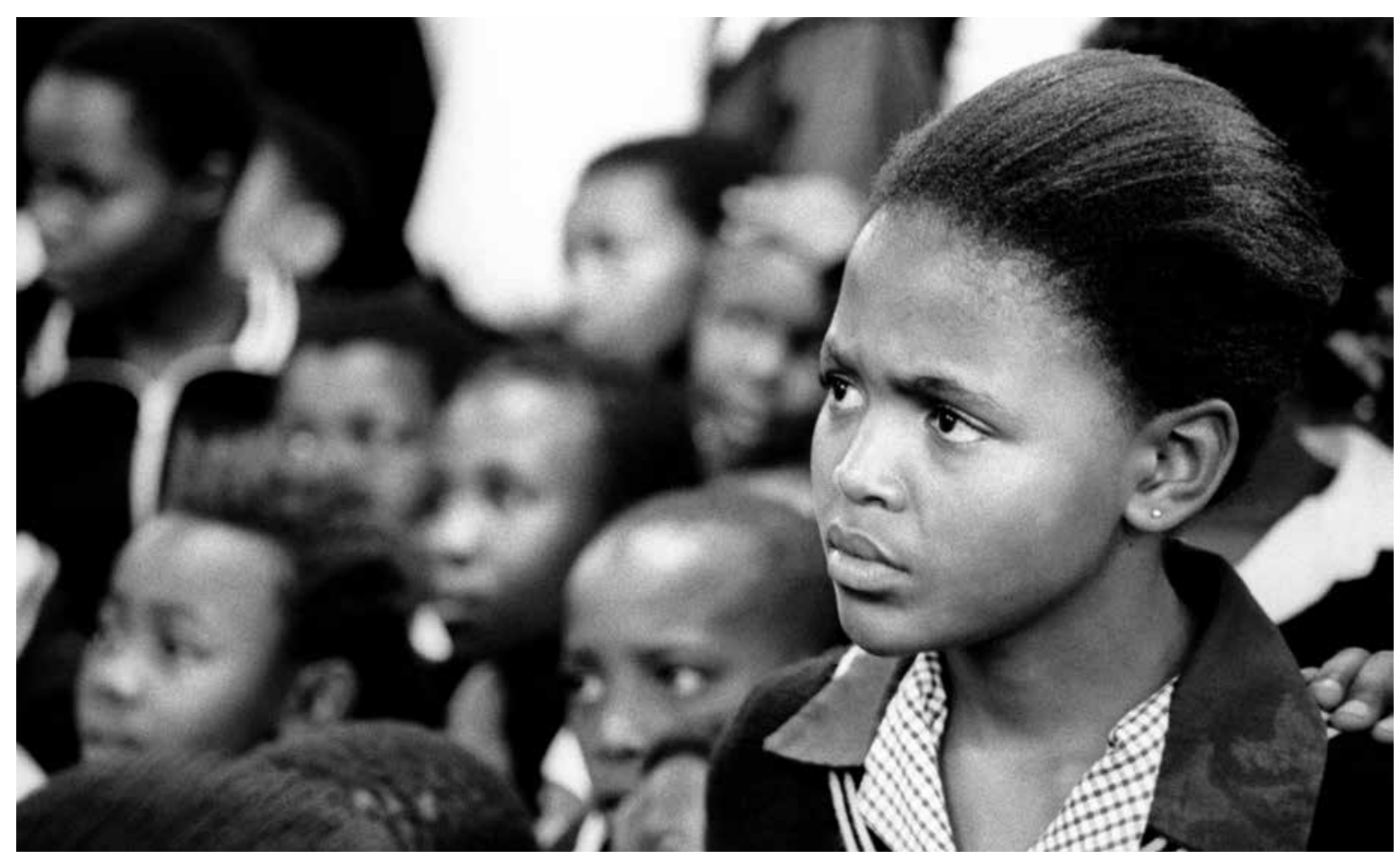

RICARDo Ramírez ARRIOLA/ARChiv0360.com • Niños de la escuela primaria Paul Mosaka observan la obra Lest Talk About It, que es parte de una campaña de concientización y prevención del VIH/Sida, presentada por el grupo Soweto Youth Drama Society. Soweto, Sudáfrica, 11 de septiembre de 2001.

del cuerpo podía causar enfermedades (Elias, 1978: $58,135)$. No era aceptable que los mocos escurrieran de la nariz: si no se tenía pañuelo, mejor dejarlos volar y pisotearlos en el suelo. Elias argumentaba que estas prescripciones reflejaban un grado creciente de vergüenza en relación con las funciones naturales del cuerpo, pero también la franqueza al sacarlas a la luz, que desaparecerían de la literatura. Advertía que con el avance de la época moderna las funciones naturales se escondían de la vista, como estaban ocultas a Lucas Alamán, mas no a Neve. Entonces aquí tenemos otro nivel de tensión entre lo público y lo privado, que es uno de los grandes temas que la biografía puede investigar, tomando en cuenta las diferencias del tiempo y el espacio.

¿Puede la historiadora llegar a una interpretación verosímil de las experiencias de Neve cuando se trata de negociar una tremenda transición de la sociedad en la segunda mitad del siglo XIX? ¿Cómo se mueve Neve de una ciudad regulada por el repique de las campanas de las iglesias a una ordenada por relojes silentes, informada por los nuevos sonidos urbanos - imagínense, como Bazant apunta, el ruido de la destrucción de conventos y la construcción de nuevos edificios-, dividida en nuevos espacios — parques, bulevares, barrios pobres separados y escondidos, calles más limpias y mejor iluminadas que formaban parte de la remodelación hausmaniana de la ciudad antigua-, captada por las nuevas maneras de ver - más y más fotografías, vitrinas de las nuevas tiendas de departamentos, formas tempranas del cine-? ¿Cómo veía, olía, sentía esta transición y cómo cambiaban sus sensaciones y sus evaluaciones? ¿Cómo se veía a sí mismo un hombre indígena en una sociedad que mantenía su mirada racista? Como Bazant es una de las historiadoras 
más creativas en México hoy, reconoce las fuentes que le ayudan a capturar la experiencia en su contexto, por ejemplo, la novela, las memorias. Tal vez Neve nunca escribió sus memorias, pero Bazant cita las del secretario particular de Maximiliano, Blasio, quien relata cómo Maximiliano tenía una noción rousseauniana de la naturaleza telúrica que lo hizo sensible al aroma de los árboles y las flores que encontró cuando viajaba en su carruaje a la escuela de Neve en Naucalpan. Bazant observa con más profundidad el repertorio cambiante y variado de músicos, cantantes y bandas. Hace referencia a los objetos materiales, por ejemplo, los dejados en prenda en las muchas casas de empeño y sus precios, que indican su valor social. Pueden ayudarle también los testamentos, los anuncios comerciales en la prensa efímera, los productos de los boticarios y sobre todo los manuales de urbanidad. Por cierto, Neve escribió un libro de texto que contiene prescripciones vigentes de la "urbanidad".

Bazant es la única historiadora en este número de Desacatos que problematiza la construcción del contexto por el autor. En los ensayos de Van Young y Spenser el contexto parece ser una historia política establecida, en el trabajo de Valero Pie hay poco contexto. Sin embargo, la construcción del contexto es tan importante como la del sujeto. De los muchos procesos históricos y acontecimientos relevantes para el sujeto, el biógrafo tiene que hacer una selección. En casos importantes, la vida del sujeto revelará los procesos y los eventos que muchas veces no son percibidos con claridad desde la historia macro. En particular, la vida de un sujeto puede revelar cómo éstos se entrelazan. Por ejemplo, en estos ensayos vemos cómo la historia económica de la posindependencia se relaciona con la política en el pensamiento y la actuación de Lucas Alamán, y en el ensayo de Spenser se explica cómo la Guerra Fría influye en la política internacional del sindicalismo y en la trayectoria de Vicente Lombardo Toledano. Lo que revela la vida de un individuo acerca de los procesos históricos y sus relaciones puede profundizar o cambiar nuestro entendimiento de un segmento del tiempo y el espacio.

Bazant es también la única de estos biógrafos que toma los temas del cuerpo, la sensación y la experiencia como elementos esenciales para entender a su sujeto. Valero los sugiere, pero como parte del pensamiento abstracto del filósofo. ¿Esta ausencia se explica porque los hombres famosos los escondían o porque el historiador tiene interés en la dimensión racional y cerebral del sujeto? Ni para los hombres famosos, con sus tomos escritos, debemos descartar la realidad que producían los cambios en la vida cotidiana, en las nociones del ser y de los otros, del cuerpo y sus funciones, de la conducta y del ejercicio de la libertad relacionados con las tecnologías cambiantes que alteran la percepción, la experiencia y la ideología. En esta observación, Elias y Walter Benjamin, sobre todo interpretado por Miriam Hansen, investigadora del cine, son útiles para atrapar algo debajo de la piel y tocarlo con el objetivo de entender lo racional y lo intelectual (Hansen y Dimendberg, 2011: 75-206). Tal vez es esto lo que Aurelia Valero Pie quiere decir del pensamiento de Gaos, pero lo deja en un marco abstracto. Una nota final: aparte de las historiadoras, no hay ninguna mujer. Su ausencia es producto de las nociones históricamente limitadas del ser, de la ideología, del poder y del cuerpo. D 


\section{Bibliografía}

Basurto, Carmen, 1941, Mi patria, libro tercero de lectura y escritura, El Material Didáctico, México.

Brown, Kate, 2009, "A Place in Biography for Oneself”, en American Historical Review, vol. 114, núm. 3: American Historical Review Roundtable: Historians and Biography, pp. 596-605.

Camarillo de Pereyra, Enriqueta, 1958, Nuevas rosas de la infancia: lecturas para niños, libro segundo para tercer año, Patria, México.

Delgadillo, Daniel, 1942, Saber leer, libro cuarto, Herrero Hermanos, México.

Elias, Norbert, 1978, History of Manners. The Civilizing Process, vol. I, Pantheon Books, Nueva York.

Ginzburg, Carlo, 1980, The Cheese and the Worms: The Cosmos of a Sixteenth-Century Miller, Johns Hopkins University Press, Baltimore.

Gusdorf, Georges, 1991, Lignes de vie, vol. 2: Auto-bio-graphie, Odile Jacob, París.

Hansen, Miriam y Edward Dimendberg, 2011, Cinema and Experience: Siegfried Kracauer, Walter Benjamin, and Theodor W. Adorno, University

of California Press, Berkeley.

Hellbeck, Jochen, 2009, "Galaxy of Black Stars: The Power of Soviet Biography”, en American Historical Review, vol. 114, núm. 3: American Historical Review Roundtable: Historians and Biography, pp. 615-624.

Kessler-Harris, Alice, 2009, "Why Biography?", en American Historical Review, vol. 114, núm. 3: American Historical Review Roundtable: Historians and Biography, pp. 625-630.

Magallón Anaya, Mario, 2009-2010, “Aproximaciones (desde la modernidad) a la filosofía de José Gaos”, en Casa del Tiempo, núm. 26-27, pp. 108-112.

Marcuse, Herbert, 1955, Eros and Civilization, Beacon Press, Boston.

Nasaw, David, 2009, "Introduction”, en American Historical Review, vol. 114, núm. 3: American Historical Review Roundtable: Historians and Biography, pp. 573-578.

Spiegel, Gabrielle M., 2008 "Comment on A Crooked Line”, en American Historical Review, vol. 113, núm. 2, pp. 406-416. 